\title{
Current Situation and Discussion of Teachers' Information Literacy in the Era of "Education Informatization 2.0"
}

\author{
You Jia \\ Dalian Naval Academy, Dalian 116018, China
}

\begin{abstract}
China's education informationization has entered a new stage of educational informationization 2.0 which integrates innovation. Based on the analysis of the connotation of educational informatization 2.0, this paper points out the importance of improving teachers' information literacy. In view of the problems existing in the current situation of teachers' overall information literacy, this paper puts forward some effective strategies to improve teachers' information literacy and integrate information technology into educational reform, such as fostering teachers' correct educational development concept, creating an information environment conducive to promoting teachers' information literacy, changing training methods and teachers' learning methods, etc. It highlights the role of educational informatization 2.0 in promoting educational modernization.
\end{abstract}

\section{Connotation of Educational Informatization 2.0}

In 2018, the Ministry of Education issued the Action Plan of Education Informatization 2.0, which put forward the development goal of "three-all, two-high and one-yearold". That is, teaching application covers all teachers, tearing application covers all school-age students, digital campus construction covers all schools, improves the application level of education informatization, and improves the information literacy of teachers and students. We have built the "Internet + education" platform. In the new era of education development, information technology has provided strong support for education development. Network and digital information have been widely integrated into teaching activities. Informatization should not only support fair and diversified education, but also pay attention to human development. Individualized and lifelong learning based on digitalization and networking has become more and more important. More important. In the process of the development of intelligent society, it will also lead to more profound changes in teaching mode. Under the background of the new era of education, the connotation of Educational Informatization 2.0 has been clear.

\subsection{The enrichment and expansion of educational resources}

In the 1.0 stage of education informatization, the focus is to re-present the business process of traditional education online. Most of the digital education resources are closely related to textbooks. Educational informationization 2.0 requires educational resources to move from exclusive use to universal use, from closed to open, and from dependence on traditional textbooks to become rich and self-organizing "big resources".

\subsection{Improvement of teachers' information literacy}

The requirement for teachers in the 1.0 stage of educational informationization is to apply information technology to educational and teaching activities. Therefore, more attention is paid to the training of teachers' information technology application ability. In the 2.0 stage of education informationization, teachers' requirements need to be improved from the application ability of information technology to the cultivation of personal overall information literacy. Only by integrating information technology into the process of education and teaching, integrating and innovating teaching contents and methods, and having good information ethics consciousness, can we become qualified teachers adapting to information-based education and teaching.

\subsection{The reform of teaching mode}

Educational Informatization 2.0 will bring about profound changes in teaching and learning for the construction of intelligent learning environment. The way to acquire knowledge is to learn from the environment, which includes teachers, learning content, learning situation, learning partners, learning networks and even intelligent agents. The main way of learning is to change from formal education to non-positive education. Teaching analysis method is no longer based on experience and causality, but mainly on data relationship analysis,

\footnotetext{
a Corresponding author: likandl@126.com
} 
providing support for teaching and educational decisionmaking through big data.

\section{Information literacy and current situation of teachers in the new era}

In the era of rapid development of educational informatization, if teachers lack sufficient information literacy, they cannot effectively cope with the challenges brought by changes in learning ways and methods. Teachers' information literacy is the key to the integration of information technology and education, and it is also an important factor in the construction of education informatization 2.0

Teachers' information literacy reflects their ability to control knowledge and information flexibly and creatively, including but not limited to the following aspects. Firstly, information consciousness has a strong sensitivity and identification ability to information. It has a profound understanding of information, information society and education informatization, and understands the value of information resources to education, teaching and students 'development. Secondly, information application ability, can skilfully apply information platform and tools, accurate and efficient access to information, screening information and effective integration, analysis and innovative use of information to solve practical problems. Thirdly, information security has a strong sense of information morality and information security. Fourth, information thinking characterized by data awareness and thinking innovation. When the value of information technology and big data analysis technology is highlighted, the thinking of big data analysis has also penetrated into the field of education. Using big data mining technology of education, we can mine educational conclusions based on statistical rules from the existing educational data of online education and course-mourning platforms, and replace the traditional experience with the analysis results. To guide the recommendation of teaching resources and teaching evaluation, so as to promote the optimization and reform of education. At the same time, in the era of big data in which information exists in the form of data, teachers should not only pay attention to how to acquire and process the existing data-based information, but also, more importantly, guide and transform the process and mechanism of information generation, exchange, Association and application around innovation in the data-based environment, which is the key point of information thinking.

From the current situation of teachers' information literacy, the development level of teachers' information literacy is far behind the demand of information literacy of teachers in education informatization 2.0. In terms of information awareness, most teachers have a one-sided understanding of education informatization and information literacy, and lack the need to improve their own information literacy level. They are not fully aware of the significance and importance of strengthening information literacy for the development of Education under the new situation. In terms of information application ability, teachers have improved the use of information platform, multimedia teaching equipment and other tools, but the ability of information acquisition, processing, summary and analysis is still lacking, which also directly affects the effect of information application and transmission, and cannot effectively apply information to specific teaching and scientific research practice. In activity. Information security awareness is relatively easy to be ignored. Even though most of the teaching activities have been presented in digital form, some teachers still have the most basic security common sense in the process of using computers and networks, such as relevant moral laws, how to effectively prevent computer viruses, and how to accurately judge the information obtained. Little is known about infringement and how to judge and resist the influence of bad information. The awareness of information security needs to be strengthened urgently. Because of teachers' lack of information literacy, the cultivation and application of information thinking only stays at the theoretical stage, and seldom applies to teaching practice.

\section{Strategies to improve teachers' information literacy in the era of educational informatization 2.0}

The core purpose of education in the new era is to promote the all-round development of students 'comprehensive qualities, such as critical thinking, complex problem solving, cooperative ability and information technology ability, by teaching them to learn. The key to the comprehensive and high-quality development of students lies in whether teachers have enough professional quality and advanced ideas that can effectively promote students 'development and learning. In the era of rapid development of educational informationization, it is urgent to improve teachers' information literacy, so that teachers can make full use of the advantages of information technology and the opportunities brought by information technology, integrate information technology organically in education and teaching, improve teaching quality and efficiency, and promote educational reform.

\subsection{Training teachers to establish correct ideas of educational development}

In the 1.0 stage of educational informationization, the informationization of educational infrastructure and environment has been basically completed, and the application of information technology in teaching activities is increasingly widespread. The key link of the integration and innovation of information technology and education lies in the establishment of the concept of student-centred educational development. Teachers' ideas about students' learning and development in the information environment should be more in line with the characteristics of the times: student-centred, technologysupported, flexible application of technology in the process of students 'learning, service and resource awareness of learning, situational learning, knowledge 
innovation in the technological environment, etc. To achieve educational equity by means of information technology, to promote educational innovation, and to improve the quality and efficiency of education.

\subsection{Creating an information environment for promoting teachers' information literacy}

It is relatively easy to fill classrooms and computer rooms with hardware. However, it is extremely difficult for teachers to actively use technology inside and outside the classroom to support students 'learning in their daily teaching activities. If there is no necessary support and motivation, teachers in the information age will still carry out teaching in the traditional way. Therefore, teachers and students need a more open and creative technological environment. In such an environment, technological integration should not be crowded out by examinationoriented education. Parents can allow their children to use information technology equipment within a reasonable range. Schools can encourage teachers to integrate information technology inside and outside classroom teaching. Teachers can give it. Students are more freer to practice the technology itself. Ultimately, teachers' beliefs, pedagogical knowledge and technical level interact with each other, and gradually integrate into school culture, thereby affecting the practice of education and teaching.

\subsection{Change the training way and teachers' learning way}

New forms of teacher mobile learning, micro-class training and MOOCs training based on Web 2.0 environment are all important ways to improve teachers' information literacy. These models can make up for many shortcomings of traditional training, and give full play to the advantages of network resource sharing and interaction. They can improve the efficiency of teachers' information literacy training, enhance teachers' professional development ability, and deepen teachers'runderstanding of the essential characteristics of information technology.

In the traditional teacher training mode, teachers' autonomous learning, cooperative learning and inquiry learning are often limited because of the factors such as teaching content and teaching objectives, learning resources acquisition, and inquiry team construction. Under the information environment, teachers can freely allocate learning time, control learning progress and choose learning methods to obtain sufficient information resources and learning materials on the network, so as to meet the professional development needs of different teachers, and ultimately achieve the improvement of teachers' disciplinary education knowledge system and the improvement of teaching effectiveness.

\section{Epilogue}

The key to the sustainability and effectiveness of education informationization lies not in the information technology equipment and its application, but in how to integrate information technology into teaching practice, thus creating a new form of education and teaching. Educational informationization stage 2.0 needs to change the direction of application-driven to innovation-led, and use information technology to support the innovation of teaching content and methods to lead the transformation and upgrading of education model in the new era. In the era of education informationization 2.0, people's expectation of education has changed to individualized development; the content of education is no longer pure subject knowledge, but more emphasis on the cultivation of learning ability; the method of education has changed from single output of teachers to more interaction between teachers and students and even human-computer interaction; the evaluation of education has changed from testing to embedded evaluation; Places for education are extended from classrooms to any place and so on. In this new situation, in order to adapt to the change of education and teaching, create a new mode of talent training, and realize equal, open and people-oriented education, teachers' information literacy and information technology integration ability cannot be effectively improved under the influence of systematic thinking. In the era of educational informationization, we should not only consolidate and strengthen the training of teachers' information technology application ability in the 1.0 stage of educational informationization, but also take the information thinking and integration innovation ability as the standard to measure teachers' information quality in the new era. Teachers should form educational ideas and concepts with information characteristics, construct their own philosophy of information-based education, and serve students 'learning and development as well as the reform of educational and teaching methods. Teachers can make full use of information platform to acquire and integrate information resources, and have the ability to use information thinking for integration and innovation, and become educators with high information literacy in the new era.

\section{References}

1. Hok Kang. How to realize the "deep integration" of information technology and education $[\mathrm{J}]$. Course, textbooks and teaching methods, 2014, (2): 58-62.

2. Wang Zhuzhu. Education Informatization 2.0: Core Essentials and Implementation Suggestions [J]. China Distance Education, 2018, (7): 5-8.

3. Sang Guoyuan, Dong Yan. On the connotation evolution and promotion strategy of teachers' information literacy in the era of "Internet + " [J]. audio-visual education research, 2016, (11): 108-112. 